\title{
3,4-Dicaffeoylquinic Acid, a Major Constituent of Brazilian Propolis, Increases TRAIL Expression and Extends the Lifetimes of Mice Infected with the Influenza A Virus
}

\author{
Tomoaki Takemura, ${ }^{1}$ Tomohiko Urushisaki, ${ }^{1}$ Mayuko Fukuoka, ${ }^{2,3}$ \\ Junji Hosokawa-Muto, ${ }^{4,5}$ Taketoshi Hata, ${ }^{1}$ Yumiko Okuda, ${ }^{4}$ Sachie Hori, ${ }^{4}$ Shigemi Tazawa, \\ Yoko Araki, ${ }^{1}$ and Kazuo Kuwata ${ }^{2,3,4}$ \\ ${ }^{1}$ Nagaragawa Research Center, API Co., Ltd., 692-3 Nagara, Gifu 502-0071, Japan \\ ${ }^{2}$ United Graduate School of Drug Discovery and Medical Information Sciences, Gifu University, 1-1 Yanagido, \\ Gifu 501-1193, Japan \\ ${ }^{3}$ CREST, Japan Science and Technology Agency, 4-1-8 Honcho, Kawaguchi, Saitama 332-0012, Japan \\ ${ }^{4}$ Center for Emerging Infectious Diseases, Gifu University, 1-1 Yanagido, Gifu 501-1194, Japan \\ ${ }^{5}$ First Department of Forensic Science, National Research Institute of Police Science, 6-3-1 Kashiwanoha, Kashiwa, Chiba \\ 277-0882, Japan
}

Correspondence should be addressed to Kazuo Kuwata, kuwata@gifu-u.ac.jp

Received 12 May 2011; Revised 4 July 2011; Accepted 4 July 2011

Academic Editor: Vincenzo De Feo

Copyright (C) 2012 Tomoaki Takemura et al. This is an open access article distributed under the Creative Commons Attribution License, which permits unrestricted use, distribution, and reproduction in any medium, provided the original work is properly cited.

Brazilian green propolis water extract (PWE) and its chemical components, caffeoylquinic acids, such as 3,4-dicaffeoylquinic acid (3,4-diCQA), act against the influenza A virus (IAV) without influencing the viral components. Here, we evaluated the anti-IAV activities of these compounds in vivo. PWE or PEE (Brazilian green propolis ethanol extract) at a dose of $200 \mathrm{mg} / \mathrm{kg}$ was orally administered to Balb/c mice that had been inoculated with IAV strain A/WSN/33. The lifetimes of the PWE-treated mice were significantly extended compared to the untreated mice. Moreover, oral administration of 3,4-diCQA, a constituent of PWE, at a dose of $50 \mathrm{mg} / \mathrm{kg}$ had a stronger effect than PWE itself. We found that the amount of tumor necrosis factor-related apoptosisinducing ligand (TRAIL) mRNA in the mice that were administered 3,4-diCQA was significantly increased compared to the control group, while H1N1 hemagglutinin (HA) mRNA was slightly decreased. These data indicate that PWE, PEE or 3,4-diCQA possesses a novel and unique mechanism of anti-influenza viral activity, that is, enhancing viral clearance by increasing TRAIL.

\section{Introduction}

Influenza is a common infectious disease, and various antiinfluenza drugs are already on the market. For example, M2 ion channel inhibitors (amantadine and rimantadine) and neuraminidase inhibitors (zanamivir, oseltamivir, etc.) have been used to treat influenza viral infections in many areas, including the United States, Europe, and Asia [13]. Although oseltamivir is one of the most popular antiinfluenza drugs, many resistant strains have already been discovered $[4,5]$. Fortunately, the resistant strains that have been found to date are not yet pandemic. However, we need to carefully monitor the emergence and prevalence of new strains with pandemic characteristics, such as the H1N1 pandemic with drug resistance, which may occur because of the high incidence of mutations [6] and genomic rearrangements [7]. To avoid the worst, the discovery of novel anti-influenza agents that do not carry the risk of creating resistant strains would be urgently required.

Propolis, a resinous substance collected by honeybees from various plant sources, is used by the bees to protect the nest entrance against intruders and bacteria. Since ancient times, it has been used as a traditional folk medicine in many countries. Recent studies have demonstrated that propolis has a wide range of pharmacological properties, including antibacterial [8-10], antioxidant [11], anti-inflammatory 
[12], and antitumor activities [13]. The activity and constituents of propolis vary with its geographical origin [14]. The differences in its constituents arise from differences in the plants from which it is sourced [15].

The antiviral activity of propolis has been reported and includes anti-BBMV [16], anti-HSV [17-21], antipoliovirus [22], anti-IBDV [10], anti-reovirus [10], antipotato viruses [23], and anti-HIV [24] activities [25, 26]. The anti-influenza activity of propolis has been also described in several reports [27-30], but the details of its activity were different. The reason for this may be differences in the plant origin of the propolis [14].

Recently, we have demonstrated that Brazilian green propolis water extract (PWE) and its components, particularly 3,4-dicaffeoylquinic acid (3,4-diCQA), have anti-IAV activity [31]. Moreover, we found that a central mechanism of these compounds is the enhancement of cellular viability via unknown cellular processes rather than activity against the viral components [31].

Here, we examined the in vivo effects of propolis extracts on the lifetimes of mice infected with the IAV. To obtain insights into the mechanism of the antiviral effects of PWE and PEE, we examined tumor necrosis factor-related apoptosis-inducing ligand (TRAIL) and IAV hemagglutinin (HA) gene expression in the lungs, because it has been reported that the ethanol extract of Polish propolis has antitumor activity via TRAIL enhancement [32].

\section{Methods}

2.1. Reagents and Compounds. Oseltamivir phosphate (Tamiflu) was purchased from the Chugai Pharmaceutical Co., Ltd. (Tokyo, Japan). Chlorogenic acid was purchased from the Tokyo Chemical Industry Co., Ltd. (Tokyo, Japan). All media and reagents for cell culture were purchased from Invitrogen (Carlsbad, CA, USA), Sigma (St. Louis, MO, USA), and Wako Pure Chemicals (Osaka, Japan). Water extracts of Brazilian green propolis (Minas Gerais State, Brazil) originating from Baccharis dracunculifolia [33] were obtained from the API Co., Ltd. (Gifu, Japan). 3,4-diCQA (99\% or $82 \%$ purity) was purified from $25 \%$ ethanolextracted Brazilian green propolis via column chromatography and HPLC (details not shown).

2.2. Mice. Female BALB/c mice ( 5 weeks old) were obtained from Japan SLC, Inc. (Hamamatsu, Japan) and housed at room temperature (maintained at $23 \pm 3^{\circ} \mathrm{C}$ ) with a relative humidity range of $32-64 \%$ and a regular $12 \mathrm{hr}$ light/dark cycle. The mice were fed a CE-2 rodent diet from CLEA Japan Inc. (Tokyo, Japan) and allowed free access to water.

2.3. Viruses. The influenza virus wild-type strain A/WSN/33 (H1N1), generated from cloned cDNAs using plasmid-based reverse genetics [34], was kindly supplied by Dr. Yoshihiro Kawaoka (Division of Virology, Department of Microbiology and Immunology, Institute of Medical Science University of Tokyo, Japan). The viruses were stored at $-80^{\circ} \mathrm{C}$ until use.

2.4. Cells. Madin-Darby canine kidney (MDCK) cells were a kind gift from Professor Hideto Fukushi (United Graduate School of Veterinary Sciences, Gifu University) and were maintained in $\alpha$-minimal essential medium (MEM) containing $10 \%$ fetal bovine serum (FBS) and penicillinstreptomycin.

\subsection{Virus Preparation in Cell Culture and Determination} of the TCID 50 Value. MDCK cells were cultured in T-75 culture flasks. Confluent cells were washed with phosphatebuffered saline (PBS) and then incubated with the virus $(0.1$ multiplicity of infection (MOI)) in $2 \mathrm{~mL}$ of viral growth medium (D-MEM (Dulbecco's Modified Eagle Medium) containing $0.625 \mu \mathrm{g} / \mathrm{mL}$ of trypsin and $0.1 \%$ bovine serum albumin (BSA)) for $1 \mathrm{hr}$ at $37^{\circ} \mathrm{C}$. Then, $10 \mathrm{~mL}$ of viral growth medium was added, and the cells were incubated for $24 \mathrm{hrs}$ at $37^{\circ} \mathrm{C}$. The culture supernatant was harvested by centrifugation $\left(3000 \mathrm{rpm}\right.$ at $\left.4^{\circ} \mathrm{C}\right)$ and stored at $-80^{\circ} \mathrm{C}$ until use. TCID $_{50}(50 \%$ tissue culture infective dose) values were determined by infecting the MDCK cells with serial dilutions of the viral suspension in 96-well microtiter plates, and the TCID $_{50}$ values were calculated using the method of Reed and Muench [35] after 6 days.

2.6. Mouse Adaptation and Preparation of Virus. Viruses that had been passaged 2 or 3 times in MDCK cells were further serially passaged in 6-week-old female BALB/c mice. The first passaged virus lot was obtained by intranasally inoculating a $20-\mu \mathrm{L}$ suspension of the starting virus $\left(5.1 \times 10^{8} \mathrm{TCID}_{50}\right.$ per $\mathrm{mL}$ ) into each animal, which had been lightly anesthetized using diethyl ether. At $48 \mathrm{hrs}$ postinoculation (hpi), the mice were sacrificed. Their lungs were removed, placed into PBS ( $2 \mathrm{~mL}$ for the lungs of two mice) supplemented with $0.1 \%$ BSA and penicillin-streptomycin, and homogenized using a PRO200 homogenizer (PRO Scientific Inc.; Oxford, CT, USA). The suspension was further centrifuged at $3000 \mathrm{rpm}$ at $4^{\circ} \mathrm{C}$, stored at $-80^{\circ} \mathrm{C}$, and termed MP1 (mouse passage 1). The subsequent passages were similarly performed by inoculating $40 \mu \mathrm{L}$ of the viral solution of the previous passage into each mouse. The second- and higher-passage virus lots were termed MP2, MP3, and so forth.

\subsection{Anti-Influenza Therapeutic Efficacy in Mice}

2.7.1. Assessment of Survival Time. Six-week-old female $\mathrm{BALB} / \mathrm{c}$ mice were lightly anesthetized with diethyl ether and inoculated with $40 \mu \mathrm{L}$ of a mixture of MP6 to MP12 (i.e., mouse-adapted viruses $\left(8.3-53 \times 10^{4} \mathrm{TCID}_{50} /\right.$ mouse, resp.)) once per day for 4 days via intranasal instillation. The mice were categorized into 6 groups: (1) control (vehicle); (2) oseltamivir phosphate $(0.5 \mathrm{mg} / \mathrm{kg}$ of body weight); (3) PWE (100 mg/kg); (4) PEE (100 mg/kg); (5) 3,4-diCQA (99\% purity; $50 \mathrm{mg} / \mathrm{kg}$ ); (6) chlorogenic acid (50 mg/kg). The compounds (in a 5\% Arabic gum solution) were orally administered to the mice twice per day at intervals of more than 6 hrs for 6 days (from 0 to $5 \mathrm{dpi}$ (days postinfection)). Administration began $4 \mathrm{hrs}$ before viral inoculation. Mouse survival was observed once per day for 12 days after viral inoculation.

2.7.2. Assessment of $m R N A$ Expression in the Lungs. Sixweek-old female BALB/c mice were lightly anesthetized with 
diethyl ether and inoculated with $20 \mu \mathrm{L}$ of MP14, a mouseadapted virus $\left(4.9 \times 10^{5} \mathrm{TCID}_{50} /\right.$ mouse $)$ once per day for 2 days via intranasal instillation. The mice were categorized into three groups: (1) control (vehicle); (2) 3,4-diCQA (82\% purity; $50 \mathrm{mg} / \mathrm{kg})$; (3) oseltamivir phosphate $(0.5 \mathrm{mg} / \mathrm{kg})$. Each compound (in a 5\% Arabic gum solution) was orally administered to the mice twice per day at 6-hour intervals for 8 days (from 0 to $7 \mathrm{dpi}$ ). Administration began $4 \mathrm{hrs}$ before viral inoculation. In the mRNA expression study ( $n=13-14$ at $0 \mathrm{dpi}$ ), the 6 mice with the lowest body weight in each group and the remaining surviving mice in each group were killed at 4 and $7 \mathrm{dpi}$, respectively, and the mRNA expression in the lungs was determined using quantitative real-time PCR (qPCR), as described below.

Total RNA was extracted from the lung homogenate using the TriPure Isolation Reagent (Roche Diagnostics, Mannheim, Germany), according to the manufacturer's protocol. Briefly, the mice were sacrificed, and their lungs were removed, placed into a solution $(1.5 \mathrm{~mL}$ for the lungs of one mouse) of TriPure, and homogenized using a PRO200 homogenizer. After centrifugation, the water phase of the lysate was recovered, and RNA was precipitated with the ethanol and rinsed. The purified RNA was dissolved in $50-100 \mu \mathrm{L}$ of nuclease-free water. The amount of RNA was estimated using a NanoDrop (Thermo Scientific, Wilmington, DE, USA). The cDNA from a 500ng aliquot was synthesized using a PrimeScript RT reagent kit (Takara Bio Inc., Shiga, Japan) and oligo dT primers as RT (reverse transcription) primers, according to the manufacturer's protocol. Quantitative real-time PCR for the IAV or mouse gene was then performed. Briefly, the aliquot of the RT reaction solution was amplified using SYBR Premix Ex Taq II (Takara Bio Inc., Shiga, Japan) and a Real-Time PCR Thermal Cycler ("Thermal Cycler Dice Real Time," Takara Bio Inc., Shiga, Japan), according to the manufacturer's protocol. H1N1-specific primers were selected based on HA (hemagglutinin) mRNA using Primer Express software (PE Applied Biosystems, Waltham, MA, USA). The sequences of the HA primer sets were $5^{\prime}$-CAATGTATGCTTTCGCACTGAGTA- $3^{\prime}$ for the forward primer and $5^{\prime}$-GACACTTCGTGTTACACTCATGCA-3' for the reverse primer. The sequences of the mouse TRAIL primer sets have been described elsewhere [36]. The mouse HPRT (hypoxanthine guanine phosphoribosyl transferase) primer sets were purchased from Takara Bio Inc. (Shiga, Japan). The relative quantities of H1N1 HA mRNA and mouse TRAIL mRNA were normalized to the mRNA expression of mouse HPRT (a housekeeping gene).

2.8. Statistics. The survival times were statistically compared using the Kaplan-Meier log-rank test and pairwise multiple comparison procedures (the Holm-Sidak method) using StatView 3.5 (SAS Institute, Cary, NC, USA). The body weights were compared using one-way analysis of variance (ANOVA). When any significance was detected by ANOVA, Dennett's nonparametric test was then applied using Ekuseru-Tokei 2006 (Social Survey Research Information Co., Ltd., Tokyo Japan). The relative mRNA expression of the target gene was compared between treatment groups using a paired $t$-test or Student's $t$-test. A $P$ value of less than $0.01(P<0.01)$ was considered to be statistically significant.

\section{Results}

3.1. PWE, PEE, and 3,4-diCQA Increase the Survival Times of Mice Infected with the Influenza Virus. In preliminary experiments, MDCK culture-derived WSN/33 (H1N1, IAV) was only moderately lethal to mice, so we adapted the parent WSN/33 to mice using serial passages to enhance its virulence [37-39], as described in the Section 2. Mouseadapted WSN/33 was able to kill more than $80 \%$ of mice within 10 days when the mice inoculated daily for 3 to 4 days. The anti-influenza activities of PWE, PEE, 3,4-diCQA, chlorogenic acid, and oseltamivir phosphate were evaluated using the mouse-adapted WSN/33 strains.

The vehicle treatment (control) group exhibited a significant decrease in body weight from 0 to $7 \mathrm{dpi}$. Treatment with PWE, PEE, or chlorogenic acid did not affect this phenotype compared to the control. However, 3,4-CQA (at 5 dpi alone, $P<0.01$ ) and oseltamivir (at $5 \mathrm{dpi}, P<0.05$; at $6-7 \mathrm{dpi}$, $P<0.01$ ) slightly and strongly, respectively, counteracted the body weight loss caused by the viral infection (Figures 1(a) and $1(\mathrm{~b})$ ).

In the same experiment, $88.9 \%$ of mice in the control group died by $12 \mathrm{dpi}$, while all of the oseltamivir-treated mice survived. The survival time of the oseltamivir group was significantly longer than that of the control group (Figure 2(a), Table 1). Moreover, although chlorogenic acid had no effect, PWE, PEE, or 3,4-CQA treatment increased the survival rate (Figures 2(a) and 2(b), Table 1).

\subsection{3,4-diCQA Increases TRAIL Expression but Decreases} HA mRNA Expression in Mouse Lungs Infected with IAV. We examined TRAIL and HA mRNA expression in the lungs of mice infected with IAV. Treatment with 3,4-CQA or oseltamivir had no effect on TRAIL mRNA expression at $4 \mathrm{dpi}$ (Figure 3). At $7 \mathrm{dpi}$, the 3,4-CQA treatment group exhibited an increase in TRAIL mRNA expression $(P<0.05)$, while the oseltamivir treatment group exhibited no change in the expression of TRAIL mRNA (Figure 3).

In the same experiment, the oseltamivir treatment group exhibited less HA mRNA expression than the control at 4 and 7 dpi $(P<0.05$; Figure 4). The 3,4-diCQA treatment group exhibited similar HA mRNA expression at 4 dpi and slightly less expression at $7 \mathrm{dpi}$ than the control group (Figure 4).

Overall, oseltamivir treatment decreased IAV HA mRNA expression rapidly after infection and had no effect on TRAIL mRNA expression, whereas 3,4-diCQA treatment moderately decreased IAV HA mRNA expression and increased TRAIL mRNA expression with a delay.

\section{Discussion}

First, we must point out that there are some controversies regarding the anti-influenza effects of various propolisrelated substances, especially in ex vivo versus in vivo experiments. We have shown that PWE and PEE can increase 


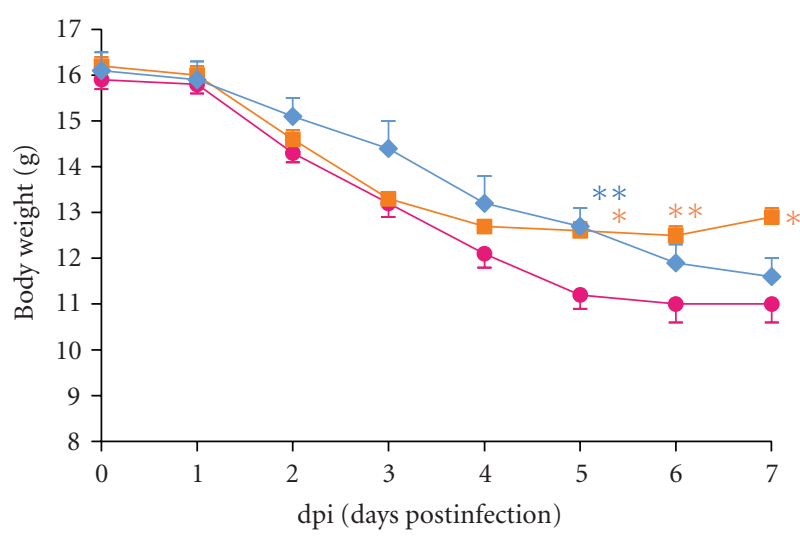

(a)

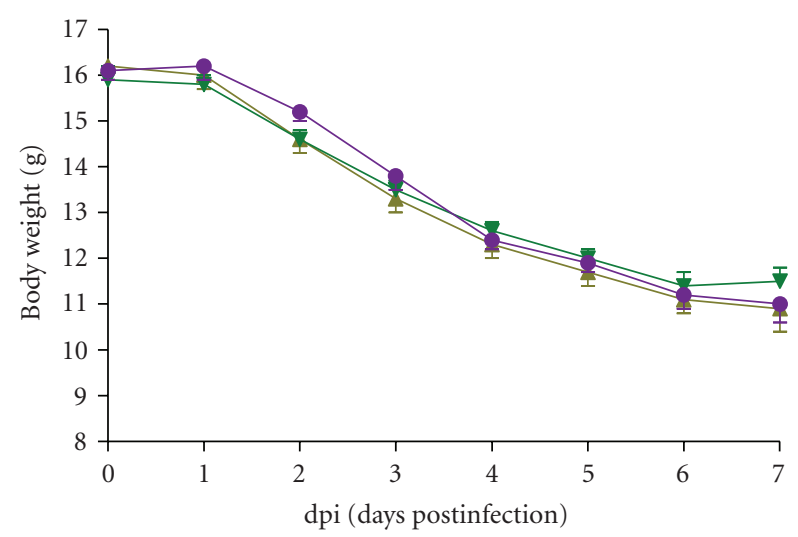

(b)

FIgURE 1: Effects of orally administrated oseltamivir phosphate, PWE, PEE, 3,4-diCQA, and chlorogenic acid on the body weight of BALB/c mice infected with the IAV. (a) control (๑), oseltamivir $(0.5 \mathrm{mg} / \mathrm{kg} ; \mathbf{\square}), 3,4$-diCQA (50 mg/kg; $),$ (b) PWE (100 mg/kg; $\mathbf{\Delta})$, PEE $(100 \mathrm{mg} / \mathrm{kg} ; \mathbf{\nabla})$, or chlorogenic acid $(50 \mathrm{mg} / \mathrm{kg}$; $)$ was administrated twice daily starting at 4 hours before the first viral infection until 5 days postinfection ( $5 \mathrm{dpi}$ ). The data represent the mean $\pm \mathrm{SE}$ for the mice that survived. $* P<0.05$ and ${ }^{* *} P<0.01$ versus vehicle control.

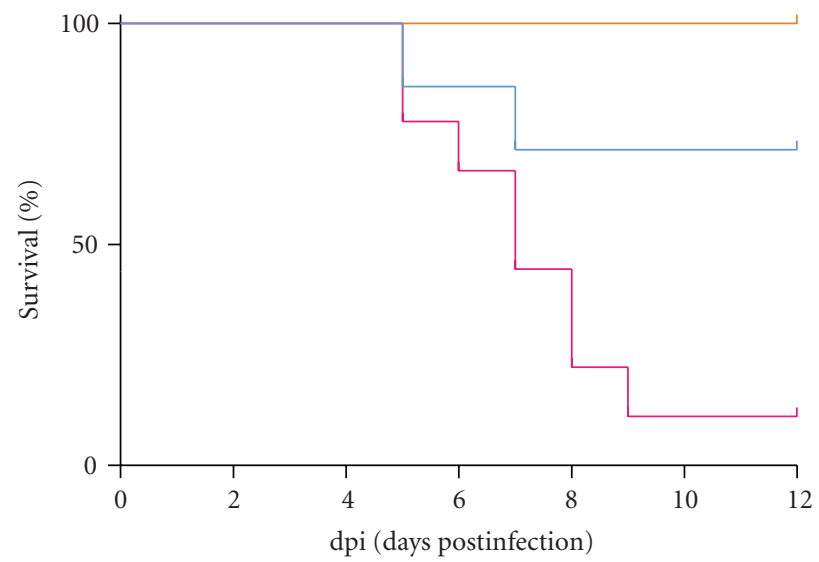

(a)

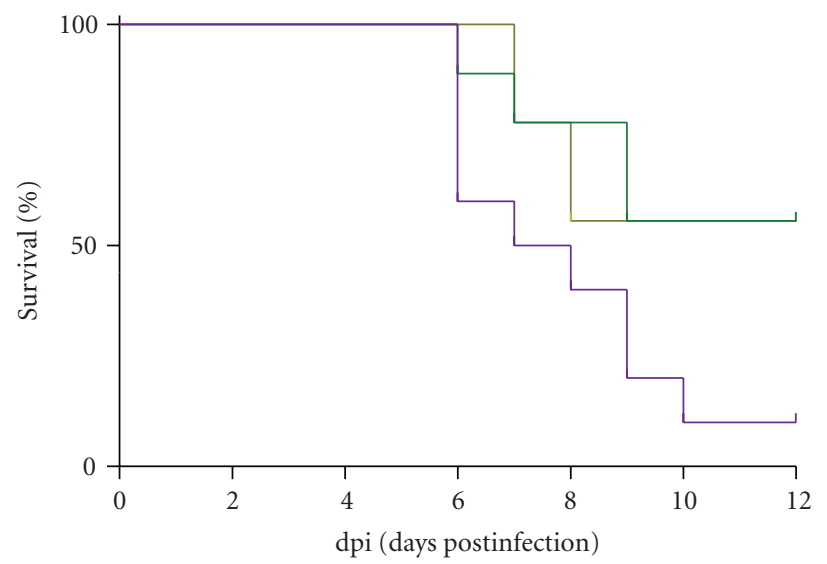

(b)

FIGURE 2: Survival curves of BALB/c mice infected with the IAV to assess the in vivo effects of orally administrated (a) control, oseltamivir $(0.5 \mathrm{mg} / \mathrm{kg}), 3,4-\mathrm{diCQA}(50 \mathrm{mg} / \mathrm{kg})$, (b) PWE (100 mg/kg), PEE (100 mg/kg), or chlorogenic acid (50 mg/kg). The colors correspond to those used in Figures 1(a) and 1(b). The infected mice were observed for 12 days. The statistical results are shown in Table 1.

the lifetimes of mice with IAV infections. In a previous report, anti-influenza activity was found for PWE [31] but not PEE (personal communication, Urushisaki T.) when using MDCK cells. Here, we speculate that, in ex vivo experiments, some substances (as yet unidentified) in PEE are cytotoxic to MDCK cells and may mask its anti-influenza activity. We have also shown that 3,4-diCQA can increase the lifetimes of mice with IAV infections (Table 1). 3,4-diCQA, a natural product, is an ester of two polyphenolic caffeic acids and one cyclitol (-)-quinic acid. While chlorogenic acid (a natural product, an ester of one caffeic acid and one cyclitol (-)-quinic acid) does not have anti-influenza activity in vivo, these two compounds have anti-influenza activity ex vivo [31]. This may occur due to differences in the pharmacokinetic properties of these compounds in vivo.

The major chemical ingredients in PWE and PEE are listed in Table $2[40,41]$, and these show that the amount of 3,4-diCQA in PWE and PEE is 3.3-6.1\% and 1.9$3.5 \%$, respectively. It must be noted that the anti-influenza activities of PWE and PEE can only be partially explained by 3,4-diCQA. Thus, it is very likely that unknown compounds that efficiently act against the IAV are also contained in PWE and PEE.

We have also shown that 3,4-diCQA increases the mRNA expression of TRAIL in the lungs of IAV-infected mice (Figure 4). Although TRAIL is an apoptosis-inducing factor in tumor cells [42], it also induces the apoptosis of influenza virus-infected cells in infected animals via the TRAIL receptor (DR5), whose expression is induced by the virus. Ishikawa et al. [36] have shown that TRAIL mRNA expression is induced by an influenza virus infection in mouse lungs, and an anti-TRAIL monoclonal antibody (mAb) delays influenza virus clearance in mice. Moreover, Brincks et al. [43] have shown that morbidity and the influenza virus 
TABLE 1: Survival of mice infected with IAV after the oral administration of various substances.

\begin{tabular}{|c|c|c|c|c|c|}
\hline Treatment & $n$ & Dose & Duration (dpi) & Survival time (dpi, mean \pm SE) & Statistical significance \\
\hline 5\% Arabic gum & 9 & & $0-5$ & $7.4 \pm 0.7$ & \\
\hline oseltamivir & 8 & $0.5 \mathrm{mg}$ twice $/ \mathrm{kg} /$ day & $0-5$ & $>12.0^{\#}$ & $* *$ \\
\hline PWE & 9 & $100 \mathrm{mg}$ twice $/ \mathrm{kg} /$ day & $0-5$ & $10.0 \pm 0.9$ & * \\
\hline PEE & 9 & $100 \mathrm{mg}$ twice/kg/day & $0-5$ & $10.1 \pm 0.9$ & * \\
\hline 3,4-diCQA & 7 & $50 \mathrm{mg}$ twice $/ \mathrm{kg} /$ day & $0-5$ & $10.3 \pm 1.5$ & $*$ \\
\hline Chlorogenic acid & 9 & $50 \mathrm{mg}$ twice $/ \mathrm{kg} /$ day & $0-5$ & $8.1 \pm 0.8$ & N.S. \\
\hline
\end{tabular}

${ }^{*}$ standard error not determined; ${ }^{*} P<0.05 ;{ }^{* *} P<0.01$; N.S. not significant.

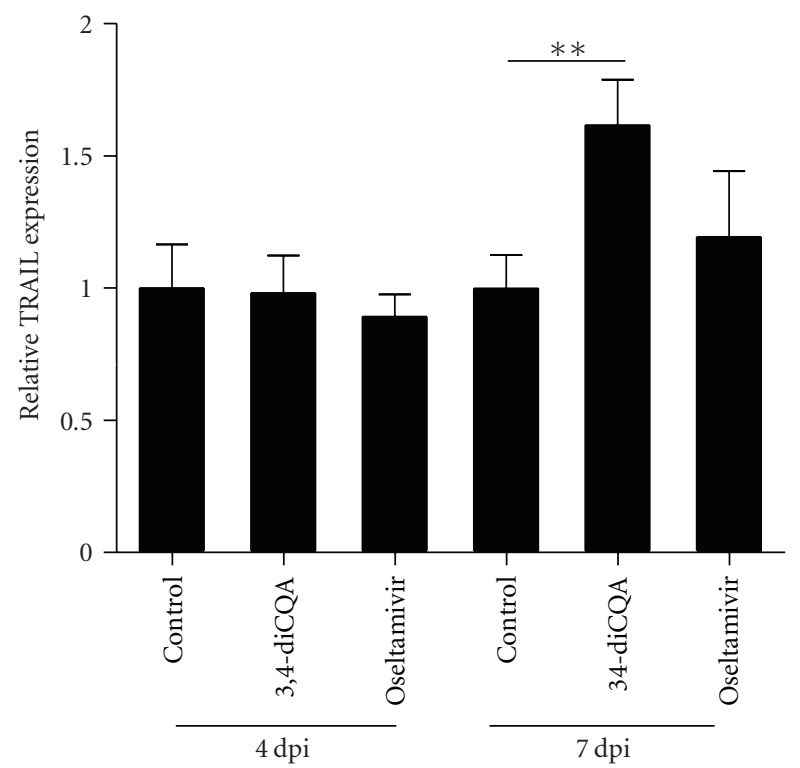

Figure 3: TRAIL expression in the lungs of BALB/c mice infected with the IAV. Vehicle, 3,4-diCQA $(50 \mathrm{mg} / \mathrm{kg})$, or oseltamivir $(0.5 \mathrm{mg} / \mathrm{kg})$ was administrated twice daily starting at $4 \mathrm{hrs}$ before the first viral infection until 7 days post-infection $(7 \mathrm{dpi})$. Total RNA was recovered at $4 \mathrm{dpi}$ or $7 \mathrm{dpi}$, and relative mRNA expression was measured using real-time PCR. The quantity of mouse TRAIL mRNA expression was normalized to the mRNA expression of mouse HPRT. The quantities are shown as mean \pm SE. ${ }^{* *} P<0.01$.

titer are increased in TRAIL-knockout (TRAIL ${ }^{-/}$) mice. Therefore, TRAIL is an important anti-influenza factor with viral clearance activity.

3,4-diCQA did not affect TRAIL expression at $4 \mathrm{dpi}$ (Figure 3). However, the infected animals were protected even at early stages of the infectious period without increased TRAIL expression because 3,4-diCQA increases the viability of infected cells, as suggested by previous ex vivo experiments [31]. It must be noted that MDCK cells do not express the TRAIL receptor [44]. 3,4-diCQA induced TRAIL mRNA at $7 \mathrm{dpi}$ relative to the control group (Figure 3). During the middle stage of infection, TRAIL expression increased, thereby increasing the lifetimes of the mice.

It has also been reported that the induction of TRAIL mRNA depends on NF- $\kappa$ B [45]. However, at the current stage, it is unclear whether the enhancement of TRAIL mRNA expression by 3,4 -diCQA is due to NF- $\kappa$ B activation.

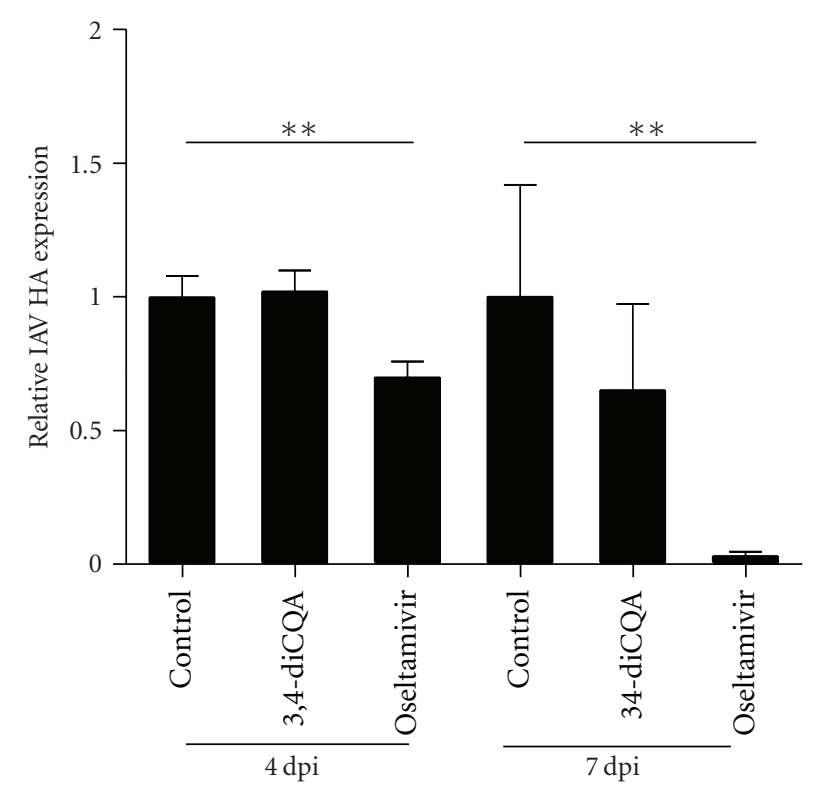

FIgURe 4: HA expression in lungs. IAV HA mRNA expression was normalized to the mRNA expression of mouse HPRT. The quantities are shown as mean \pm SE. ${ }^{* *} P<0.01$ (Student's $t$-test).

We confirmed that Brazilian green propolis extracts (PWE and PEE) have anti-influenza activities. Here, we also hypothesized that their mode of action at least partially includes two mechanisms: an unknown cytoprotective mechanism [31] and the enhancement of viral clearance via TRAIL overexpression. We hypothesize that both are induced by 3,4-diCQA and/or unknown active constituents of Brazilian green propolis.

An important point regarding our hypothesis concerning the anti-influenza effects of propolis or its constituent, 3,4-diCQA, is that it might trigger or enhance the selfdefense machineries of the host. Although viruses can easily become resistant to anti-influenza drugs, such as oseltamivir, that directly target viral proteins $[4,5]$, it would be more difficult for viruses to become resistant to antiviral agents whose target molecules are host molecules or machineries. Therefore, health supplements such as propolis may be useful as an alternative strategy for protection against influenza virus infections.

Many traditional Chinese medicinal herbs appear to have potential anti-influenza effects [46], but their mechanisms 
TABLE 2: Concentrations and molecular weights of the constituents of Brazilian green propolis [40, 41].

\begin{tabular}{|c|c|c|c|}
\hline Components & $\begin{array}{c}\text { Content } \\
(\mathrm{w} / \mathrm{w} \%) \text { in } \\
\text { PWE }\end{array}$ & $\begin{array}{c}\text { Content } \\
(\mathrm{w} / \mathrm{w} \%) \text { in } \\
\text { PEE }\end{array}$ & $\begin{array}{c}\text { Molecular } \\
\text { weight } \\
(\mathrm{g} / \mathrm{mol}) \\
\end{array}$ \\
\hline Chlorogenic acid & $2.7-3.6$ & $0.6-0.8$ & 354.3 \\
\hline Caffeic acid & 0.2 & $0.1-0.6$ & 180.2 \\
\hline $\begin{array}{l}\text { 3,5-dicaffeoylquinic } \\
\text { acid }\end{array}$ & $4.3-4.9$ & $2.4-2.7$ & 516.5 \\
\hline $\begin{array}{l}\text { 3,4-dicaffeoylquinic } \\
\text { acid }\end{array}$ & $3.3-6.1$ & $1.9-3.5$ & 516.5 \\
\hline $\begin{array}{l}\text { 4,5-dicaffeoylquinic } \\
\text { acid }\end{array}$ & — & — $^{\#}$ & 516.5 \\
\hline $\begin{array}{l}\text { 3,4,5-tricaffeoylquinic } \\
\text { acid }\end{array}$ & 0.2 & 0.6 & 678.6 \\
\hline Artepillin C & $0.2-0.6$ & $11.4-14.0$ & 300.4 \\
\hline Baccharin & 0.0 & 6.8 & 562.6 \\
\hline Drupanin & 0.1 & 1.8 & 232.3 \\
\hline Isosakuranetin & — & 1.2 & 286.3 \\
\hline$p$-coumaric acid & 3.7 & $2.3-2.5$ & 164.2 \\
\hline Ferulic acid & 0.1 & $0.0-0.1$ & 194.2 \\
\hline Quinic acid & — & — & 192.2 \\
\hline
\end{tabular}

\#Data not available.

are not well understood. Our findings show that PWE and PEE and their constituent, 3,4-diCQA, may be useful as a potent lead compound for anti-influenza medicine. This may promote research into anti-influenza medicine developed from traditional substances.

\section{Acknowledgments}

The authors thank Professor Hideto Fukushi and Professor Yoshihiro Kawaoka for their donation of the influenza virus. They also thank Mr. Takayuki Ohyama (Life Science Research Center, Gifu University) for kind support and maintenance of the P3 level animal experimentation room. This work was supported by API Co., Ltd. (Gifu, Japan). The experiments were carried out at the Center for Emerging Infectious Diseases (CEID), Gifu University.

\section{References}

[1] F. G. Hayden, A. D. M. E. Osterhaus, J. J. Treanor et al., "Efficacy and safety of the neuraminidase inhibitor zanamivir in the treatment of influenza virus infection," The New England Journal of Medicine, vol. 337, pp. 874-880, 1997.

[2] K. G. Nicholson, F. Y. Aoki, A. D. Osterhaus et al., "Efficacy and safety of Oseltamivir in treatment of acute influenza: a randomised controlled trial. Neuraminidase Inhibitor Flu Treatment Investigator Group," The Lancet, vol. 355, pp. 1845$1850,2000$.

[3] J. J. Treanor, F. G. Hayden, P. S. Vrooman et al., "Efficacy and safety of the oral neuraminidase inhibitor oseltamivir in treating acute influenza: a randomized controlled trial," Journal of the American Medical Association, vol. 283, no. 8, pp. 1016-1024, 2000.
[4] M. A. Ciblak, M. Hasoksuz, V. Escuret et al., "Surveillance and oseltamivir resistance of human influenza A virus in Turkey during the 2007-2008 season," Journal of Medical Virology, vol. 81, no. 9, pp. 1645-1651, 2009.

[5] D. Tamura, K. Mitamura, M. Yamazaki et al., "Oseltamivirresistant influenza A viruses circulating in Japan," Journal of Clinical Microbiology, vol. 47, no. 5, pp. 1424-1427, 2009.

[6] S. Aggarwal, B. Bradel-Tretheway, T. Takimoto, S. Dewhurst, and B. Kim, "Biochemical characterization of enzyme fidelity of influenza a virus RNA polymerase complex," PLOS ONE, vol. 5, no. 4, article e10372, 2010.

[7] M. I. Nelson, C. Viboud, L. Simonsen et al., "Multiple reassortment events in the evolutionary history of $\mathrm{H} 1 \mathrm{~N} 1$ influenza A virus since 1918," PLoS Pathogens, vol. 4, no. 2, article e1000012, 2008.

[8] V. Bankova, M. C. Marcucci, S. Simova, N. Nikolova, A. Kujumgiev, and S. Popov, "Antibacterial diterpenic acids from Brazilian propolis," Zeitschrift fur Naturforschung, vol. 51, no. 5-6, pp. 277-280, 1996.

[9] L. Drago, B. Mombelli, E. De Vecchi, M. C. Fassina, L. Tocalli, and M. R. Gismondo, "In vitro antimicrobial activity of propolis dry extract," Journal of Chemotherapy, vol. 12, no. 5, pp. 390-395, 2000.

[10] F. K. Abd El Hady and A. G. Hegazi, "Egyptian propolis: 2. Chemical composition, antiviral and antimicrobial activities of East Nile Delta propolis," Zeitschrift fur Naturforschung, vol. 57, no. 3-4, pp. 386-394, 2002.

[11] Y. Nakajima, M. Shimazawa, S. Mishima, and H. Hara, "Water extract of propolis and its main constituents, caffeoylquinic acid derivatives, exert neuroprotective effects via antioxidant actions," Life Sciences, vol. 80, no. 4, pp. 370-377, 2007.

[12] O. K. Mirzoeva and P. C. Calder, "The effect of propolis and its components on eicosanoid production during the inflammatory response," Prostaglandins Leukotrienes and Essential Fatty Acids, vol. 55, no. 6, pp. 441-449, 1996.

[13] C. N. Chen, M. S. Weng, C. L. Wu, and J. K. Lin, “Comparison of radical scavenging activity, cytotoxic effects and apoptosis induction in human melanoma cells by taiwanese propolis from different sources," Evidence-Based Complementary and Alternative Medicine, vol. 1, pp. 175-185, 2004.

[14] A. Kujumgiev, I. Tsvetkova, Y. Serkedjieva, V. Bankova, R. Christov, and S. Popov, "Antibacterial, antifungal and antiviral activity of propolis of different geographic origin," Journal of Ethnopharmacology, vol. 64, no. 3, pp. 235-240, 1999.

[15] K. R. Markham, K. A. Mitchell, A. L. Wilkins, J. A. Daldy, and Y. Lu, "HPLC and GC-MS identification of the major organic constituents in New Zealand propolis," Phytochemistry, vol. 42, no. 1, pp. 205-211, 1996.

[16] R. F. Mohamed and A. A. Owayss, "An inhibitory activity of propolis extract against broadbean mottle bromovirus (BBMV)," International Journal of Virology, vol. 1, no. 1, pp. 31-31, 2005.

[17] M. Amoros, C. M. O. Simoes, L. Girre, F. Sauvager, and M. Cormier, "Synergistic effect of flavones and flavonols against herpes simplex virus type 1 in cell culture. Comparison with the antiviral activity of propolis," Journal of Natural Products, vol. 55, no. 12, pp. 1732-1740, 1992.

[18] M. Amoros, E. Lurton, J. Boustie, L. Girre, F. Sauvager, and M. Cormier, "Comparison of the anti-herpes simplex virus activities of propolis and 3- methyl-but-2-enyl caffeate," Journal of Natural Products, vol. 57, no. 5, pp. 644-647, 1994.

[19] M. Huleihel and V. Isanu, "Anti-herpes simplex virus effect of an aqueous extract of propolis," Israel Medical Association Journal, vol. 4, no. 11, pp. 923-927, 2002. 
[20] S. Nolkemper, J. Reichling, K. H. Sensch, and P. Schnitzler, "Mechanism of herpes simplex virus type 2 suppression by propolis extracts," Phytomedicine, vol. 17, no. 2, pp. 132-138, 2010.

[21] P. Schnitzler, A. Neuner, S. Nolkemper et al., "Antiviral activity and mode of action of propolis extracts and selected compounds," Phytotherapy Research, vol. 24, no. 1, pp. S20S28, 2010.

[22] M. C. Búfalo, A. S. Figueiredo, J. P. B. De Sousa, J. M. G. Candeias, J. K. Bastos, and J. M. Sforcin, "Anti-poliovirus activity of Baccharis dracunculifolia and propolis by cell viability determination and real-time PCR," Journal of Applied Microbiology, vol. 107, no. 5, pp. 1669-1680, 2009.

[23] F. G. Fahmy and M. O. Omar, "Effect of propolis extract on certain potato viruses," in Proceedings of the 4th International Conference on Apiculture in Tropical Climates, pp. 56-60, Cairo, Egypt, November 1989.

[24] J. Ito, F. R. Chang, H. K. Wang et al., "Anti-AIDS agents. 48. Anti-HIV activity of moronic acid derivatives and the new melliferone-related triterpenoid isolated from Brazilian propolis," Journal of Natural Products, vol. 64, no. 10, pp. 1278-1281, 2001.

[25] V. Maximova-Todorova, N. Manolova, and G. Gegova, "Antiviral effects of some fractions isolated from propolis," Acta Microbiologica Bulgarica, vol. 17, pp. 79-85, 1985.

[26] M. Amoros, F. Sauvager, L. Girre, and M. Cormier, "In vitro antiviral activity of propolis," Apidologie, vol. 23, pp. 231-240, 1992.

[27] L. F. Shevchenko et al., The propolis Information Bureau, 1971.

[28] V. Esanu, E. Prahoveanu, J. Crisan, and A. Cioca, "The effect of an aqueous propolis extract, of rutin and of a rutin-quercetin mixture on experimental influenza virus infection in mice," Revue Roumaine de Medecine-Serie de Virologie, vol. 32, no. 3, pp. 213-215, 1981.

[29] J. Serkedjieva, N. Manolova, and V. Bankova, "Anti-influenza virus effect of some propolis constituents and their analogues (esters of substituted cinnamic acids)," Journal of Natural Products, vol. 55, no. 3, pp. 294-297, 1992.

[30] T. Shimizu, A. Hino, A. Tsutsumi, K. P. Yong, W. Watanabe, and M. Kurokawa, "Anti-influenza virus activity of propolis in vitro and its efficacy against influenza infection in mice," Antiviral Chemistry and Chemotherapy, vol. 19, no. 1, pp. 713, 2008.

[31] T. Urushisaki, T. Takemura, S. Tazawa et al., "Caffeoylquinic acids are major constituents with potent anti-influenza effects in Brazilian green propolis water extract," Evidence-Based Complementary and Alternative Medicine, vol. 2011, Article ID 254914, 7 pages, 2011.

[32] A. Ewelina, P. C. Zenon, B. Joanna, M. Anna, P. Andrej, and K. Wojciech, "Ethanolic extract of propolis augments TRAILinduced apoptotic death in prostate cancer cells," EvidenceBased Complementary and Alternative Medicine, vol. 2011, Article ID 535172, 11 pages, 2011.

[33] S. Kumazawa, M. Yoneda, I. Shibata, J. Kanaeda, T. Hamasaka, and T. Nakayama, "Direct evidence for the plant origin of Brazilian propolis by the observation of honeybee behavior and phytochemical analysis," Chemical and Pharmaceutical Bulletin, vol. 51, no. 6, pp. 740-742, 2003.

[34] G. Neumann, T. Watanabe, H. Ito et al., "Generation of influenza A viruses entirely from cloned cDNAs," Proceedings of the National Academy of Sciences of the United States of America, vol. 96, no. 16, pp. 9345-9350, 1999.

[35] L. J. Reed and H. Muench, "A simple method of estimating fifty per cent endpoints," American Journal of Epidemiology, vol. 27, no. 3, pp. 493-497, 1938.
[36] E. Ishikawa, M. Nakazawa, M. Yoshinari, and M. Minami, "Role of tumor necrosis factor-related apoptosis-inducing ligand in immune response to influenza virus infection in mice," Journal of Virology, vol. 79, no. 12, pp. 7658-7663, 2005.

[37] G. K. Hirst, "Studies on the mechanism of adaptation of influenza virus to mice," The Journal of Experimental Medicine, vol. 86, pp. 357-366, 1947.

[38] S. Raut, J. Hurd, G. Blandford, R. B. Heath, and R. J. Cureton, "The pathogenesis of infections of the mouse caused by virulent and avirulent variants of an influenza virus," Journal of Medical Microbiology, vol. 8, no. 1, pp. 127-136, 1975.

[39] P. R. Wyde, R. B. Couch, and B. F. Mackler, "Effects of low and high passage influenza virus infection in normal and nude mice," Infection and Immunity, vol. 15, no. 1, pp. 221-229, 1977.

[40] S. Mishima, C. Yoshida, S. Akino, and T. Sakamoto, "Antihypertensive effects of Brazilian propolis: identification of caffeoylquinic acids as constituents involved in the hypotension in spontaneously hypertensive rats," Biological and Pharmaceutical Bulletin, vol. 28, no. 10, pp. 1909-1914, 2005.

[41] H. Izuta, Y. Narahara, M. Shimazawa, S. Mishima, S. I. Kondo, and H. Hara, "1,1-diphenyl-2-picrylhydrazyl radical scavenging activity of bee products and their constituents determined by ESR," Biological and Pharmaceutical Bulletin, vol. 32, no. 12, pp. 1947-1951, 2009.

[42] B. Bonavida, C. P. Ng, A. Jazirehi, G. Schiller, and Y. Mizutani, "Selectivity of TRAIL-mediated apoptosis of cancer cells and synergy with drugs: the trail to non-toxic cancer therapeutics (review)," International Journal of Oncology, vol. 15, no. 4, pp. 793-802, 1999.

[43] E. L. Brincks, A. Katewa, T. A. Kucaba, T. S. Griffith, and K. L. Legge, "CD8 T cells utilize TRAIL to control influenza virus infection," Journal of Immunology, vol. 181, no. 7, pp. 49184925, 2008.

[44] R. C. Elders, S. J. Baines, and B. Catchpole, "Susceptibility of the C2 canine mastocytoma cell line to the effects of tumor necrosis factor-related apoptosis-inducing ligand (TRAIL)," Veterinary Immunology and Immunopathology, vol. 130, no. 12, pp. 11-16, 2009.

[45] W. J. Wurzer, C. Ehrhardt, S. Pleschka et al., "NF$\kappa \mathrm{B}$-dependent induction of tumor necrosis factor-related apoptosis-inducing ligand (TRAIL) and Fas/FasL is crucial for efficient influenza virus propagation," Journal of Biological Chemistry, vol. 279, no. 30, pp. 30931-30937, 2004.

[46] X. Y. Chen, T. X. Wu, G. J. Liu et al., "Chinese medicinal herbs for influenza," Cochrane Database of Systematic Reviews, no. 4, Article ID CD004559, 2007. 


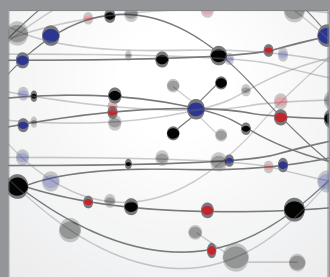

The Scientific World Journal
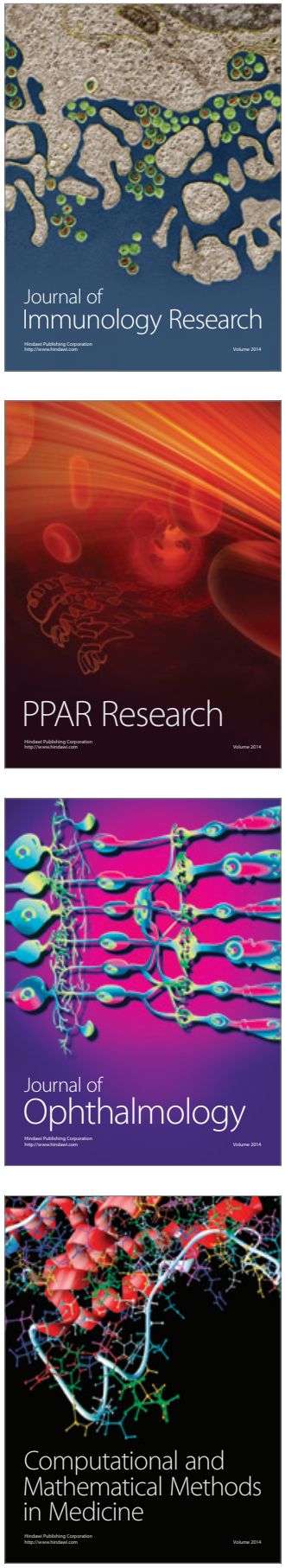

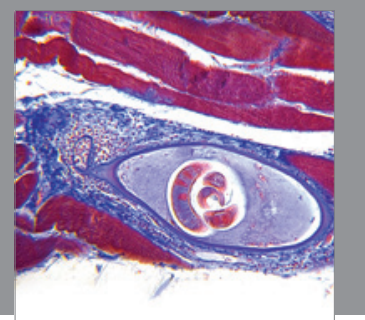

Gastroenterology

Research and Practice
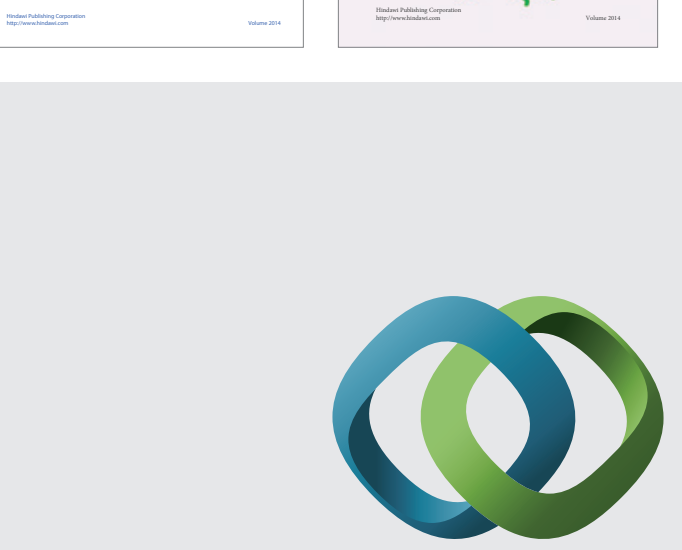

\section{Hindawi}

Submit your manuscripts at

http://www.hindawi.com
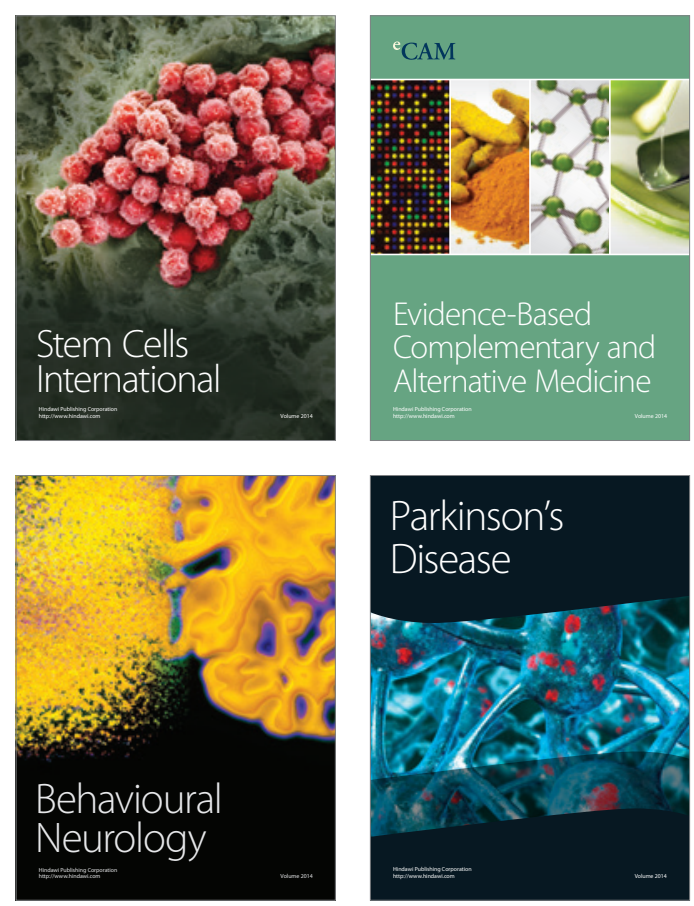

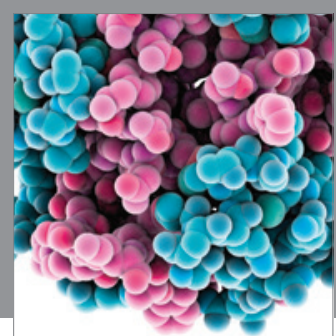

Journal of
Diabetes Research

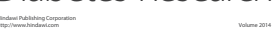

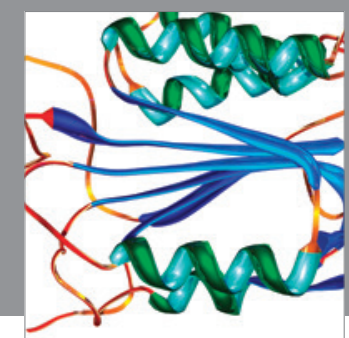

Disease Markers
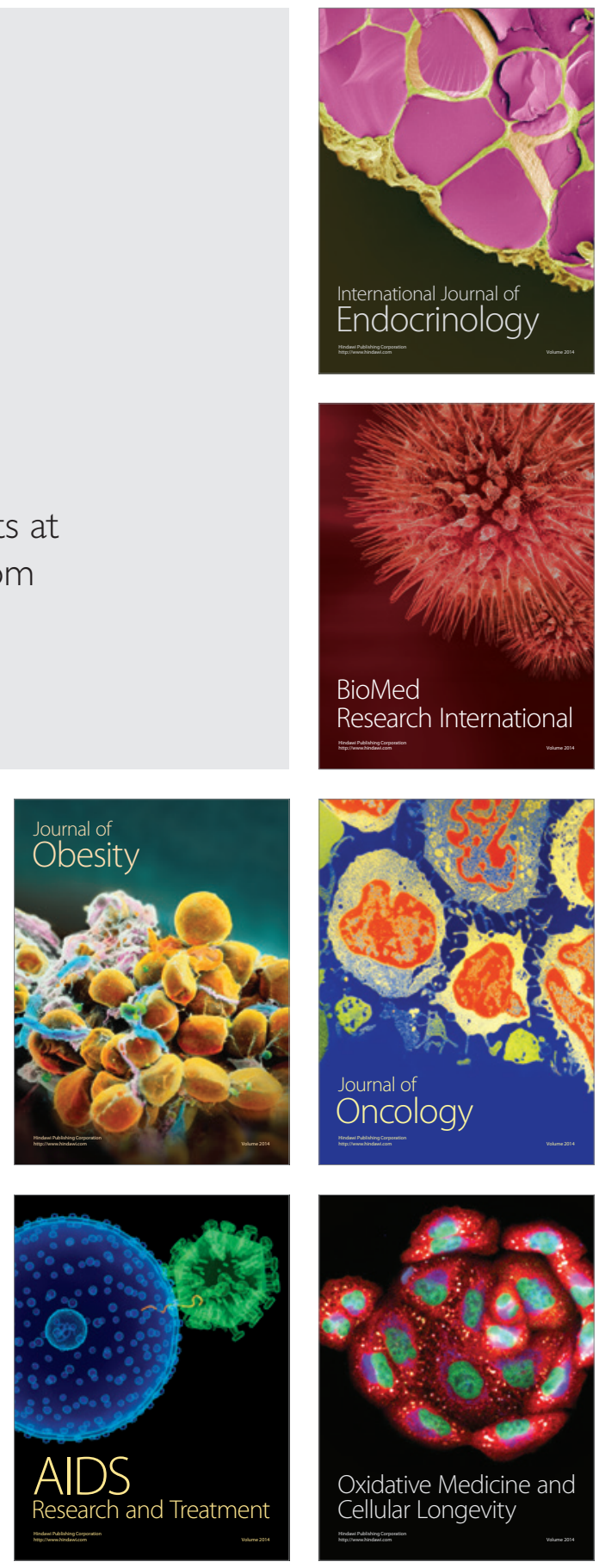